\title{
Presentation of a flashing light following one-trial fear conditioning enhances retention
}

\author{
RITA Y. EMMERSON and TERRY L. DeVIETTI \\ Central Washington University, Ellensburg, Washington
}

\begin{abstract}
Rats exposed for $60 \mathrm{sec}$ to a flashing light stimulus following one-trial fear conditioning showed enhanced retention performance relative to controls not exposed to the flashing light. The results of a second experiment demonstrated a time-dependent gradient of the enhancement effect. In view of additional data indicating that the flashing light is not aversive, these results suggest that the presentation of an exteroceptive stimulus can influence memory processing.
\end{abstract}

Previous research from our laboratory indicated that stimulation of the mesencephalic reticular formation (MRF) in rats immediately following onetrial fear conditioning enhanced retention performance (DeVietti \& Kirkpatrick, 1977). Furthermore, varying the length of the interval between the training trial and MRF stimulation produced a gradient of enhancement such that the later in time the stimulation followed the training trial, the less the enhancement was, until, at $1 \mathrm{~h}$ following training, stimulation of the MRF had no effect on subsequent retention performance (DeVietti, Conger, \& Kirkpatrick, 1977). These experiments included a variety of tests to assess possible aversive consequences of the MRF stimulation; if found, such aversive consequences would seriously alter the interpretation of the data. None of these tests gave any indication that the MRF stimulation was aversive. However, the data from these tests were less than compelling, because the evidence supporting the conclusion that MRF stimulation was not aversive rested on failures to obtain a significant effect of the stimulation.

We recently used another test for aversiveness of MRF stimulation: a latent inhibition paradigm (DeVietti, Wittman, Emmerson, \& Thatcher, 1981). In that study, the to-be-conditioned stimulus, a tone, was presented to rats on several occasions prior to fear conditioning in which the tone was paired with footshock; the fear conditioning resulted in attenuated retention performance relative to that of controls not given the preexposure experience. Relative to these baselines, rats given stimulation of the MRF after each preexposure trial showed increased latent inhibition in the test. If stimulation of the MRF were

This research was supported in part by the small grants program of Central Washington University. We gratefully acknowledge the assistance of Jim Thomson, Tim Wittman, and Kevin Daly. Requests for reprints should be sent to Terry L. DeVietti, Psychology Department, Central Washington University, Ellensburg, Washington 98926. aversive, one would expect decreased latent inhibition in these animals, since such assumed aversiveness would be expected to summate with the aversiveness of footshock. An additional group of rats were exposed to a flashing light following each preexposure to the tone, because Lubow, Schnur, and Rifkin (1976) had reported that the presentation of a second stimulus in the preexposure trials disrupted the development of latent inhibition. However, in our experiment, the presentation of the flashing light facilitated development of latent inhibition to the same extent as stimulation of the MRF. The MRF data are consistent with the idea that such stimulation enhances memory processing and with an explanation of latent inhibition that holds that the organism learns to "ignore" (Mackintosh, 1975) or "tune out" (Solomon \& Moore, 1975) the irrelevant stimulus during the preexposure trials. Since presentation of the flashing light also increased latent inhibition, we suspected that this stimulus might also affect retention performance when used as a posttraining treatment. The present experiments were designed to explore this possibility.

\section{EXPERIMENT 1}

Experiment 1 was designed to determine whether $60 \mathrm{sec}$ of a flashing light following fear conditioning would increase retention performance in a drinksuppression task.

\section{Method}

Subjects. The subjects were 64 male Long-Evans rats from the Central Washington University Psychology Department animal colonies, and were $90-120$ days of age at the beginning of the experiment.

Apparatus. Two identical chambers measuring $20 \times 30 \times$ $30 \mathrm{~cm}$ were used for training and testing. The sides and top were Plexiglas, and the back and front were aluminum painted flat gray. The grid floor was made of .64-cm-diameter stainless steel rods spaced $1.9 \mathrm{~cm}$ on center. A circular opening in the front wall was just large enough to allow the insertion of a drinking tube 
$5 \mathrm{~cm}$ from the side and $8 \mathrm{~cm}$ from the grid floor of the chamber. A drinkometer circuit that monitored contact with the drinking tube was formed between the water in the tube and the grid floor. The conditioned stimulus, a $15-\mathrm{sec}, 1200-\mathrm{Hz}, 90-\mathrm{dB}(\mathrm{SPL})$ tone, was delivered from a Heathkit tone generator through $10-\mathrm{cm}$ loudspeakers positioned at floor level behind the rear wall of each chamber. The unconditioned stimulus was $1.0-\mathrm{mA}$ scrambled footshock $(60 \mathrm{~Hz}, 206 \mathrm{~V} \mathrm{rms})$ delivered through the grid floor. Both chambers were individually enclosed in fan-ventilated, soundattenuating boxes, with a $25-\mathrm{W}$ bulb attached to the ceiling of each box. This source of illumination was constantly on, except when programmed to flash at $1.5 \mathrm{~Hz}$ in a repeating pattern of $6 \mathrm{sec}$ flash $/ 3 \mathrm{sec}$ on, during the appropriate times in the experimental procedure. Additional apparatus included electromechanical programming equipment located in a room adjacent to the two rooms containing the training and testing chambers.

Procedure. Animals were individually housed and maintained on food and water ad lib throughout the experiment, except that water was withheld $24 \mathrm{~h}$ prior to drink training and testing.

On the 1st day of the experiment, all animals were handled for 5 min. During the next 4 days, animals were familiarized with various aspects of the experimental situation, according to the following schedule: On Day 2, each rat was placed in one of the two chambers for $10 \mathrm{~min}$ and water was removed from the home cage. On Day 3, each rat, now $24 \mathrm{~h}$ water deprived, was taken to the chamber, its nose touched to the drinking tube (now present in the chamber), and released near the rear of the chamber. After the animal had completed a total of 110 licks from the drinking tube, it was returned to the home cage. Water was returned to all home cages at the conclusion of this drink training session. On Day 4, each animal was placed in the chamber for $1 \mathrm{~min}$ and the home cage water was again removed. On Day 5 , all animals received the same treatment as on Day 3, and, at the end of this session, water was returned to all the home cages. The drinking tube was present in the chambers only during the 2 drink training days and during the test day session.

The following day, the animals were randomly assigned to one of four groups. Training in the forward-conditioned groups consisted of placing the animal in the training-testing apparatus and, after $1 \mathrm{~min}$, presenting the 15 -sec tone, with footshock delivered during the 15 th sec. Half of these animals also received $60 \mathrm{sec}$ of programmed light flash immediately following offset of tone and footshock. In the backward-conditioned groups, each animal was placed in the training-testing apparatus and, $39 \mathrm{sec}$ later, received $1 \mathrm{sec}$ of footshock; then, after $20 \mathrm{sec}$, the $15-\mathrm{sec}$ tone was presented. Half of the backward-conditioned animals also experienced $60 \mathrm{sec}$ of programmed light flash immediately following tone offset. Animals in all groups were removed from the apparatus $70 \mathrm{sec}$ after tone offset and were returned to the home cage, from which water had again been removed.

Twenty-four hours later, all animals were tested according to the procedure described for Days 3 and 5 except that, after the animal had completed 100 licks from the drinking tube, the tone was automatically presented and remained on until the animal had completed an additional 10 licks in the presence of the tone.

The time (in seconds) for each animal to complete the initial 100 licks and the time to complete an additional 10 licks were automatically recorded and served as data for analysis. Animals that did not drink within $600 \mathrm{sec}$ after the onset of the tone were assigned a score of 600 . The experiment was run in two replications, with equal numbers of rats in each group in each replication.

\section{Results}

The data from one animal in the backwardconditioned, no-light-flash condition were eliminated from consideration because of procedural error.

The amount of time to complete the initial 100 licks from the drinking tube on the test day was analyzed with a $2 \times 2$ unweighted means analysis of variance, with groups (forward or backward conditioned) and light flash (present or absent) serving as the main factors. The analysis revealed no effect of groups, light flash, or their interaction (all Fs $>1$ ).

The main data on the latency to complete 10 additional licks in the presence of the test tone are summarized in Table 1 . A $2 \times 2$ unweighted means analysis of variance revealed a significant effect of the training conditions $[F(1,59)=55.01, p<.001]$ and a significant effect of the light-flash conditions $[F(1,59)$ $=10.97, \mathrm{p}<.01]$. In addition, the interaction of these two main effects was statistically significant $[F(1,59)=6.38, p<.02]$. The analysis of the simple main effects of this interaction revealed that the light flash did not differentiate test performance in the backward-conditioned groups $[F(1,59)>1]$, but that in the forward-conditioned groups light-flash stimulation increased retention performance $[F(1,59)=$ $17.03, \mathrm{p}<.001$ ]. Also, as part of the analysis of simple main effects, forward conditioning resulted in longer test latencies than did backward conditioning in both the light-flash $[\mathrm{F}(1,59)=49.43, \mathrm{p}<.001]$ and the no-light-flash $[\mathrm{F}(1,59)=11.97, \mathrm{p}<.01]$ conditions

\section{Discussion}

The results of Experiment 1 demonstrate that the flashing light increases retention performance in a traditional fear-conditioning paradigm. Since all animals (except for those who also experienced the flashing light) in the forward-conditioned groups received the same training, the increase in retention performance in these animals is attributed to the addition of the flashing light. There is reason to believe that the effect of this stimulus was specific to retention of conditioning, since differential experience with the flashing light did not affect the initial 100 lick latencies on the test day. Furthermore, the backward-conditioned groups experienced the same aspect of the training situation as the forwardconditioned animals. Yet, when the tone and footshock presentations were noncontingent, the flashinglight experience had no measurable effect on performance.

Table 1

Latency to Complete 10 Licks After Tone Onset

\begin{tabular}{lcccccc}
\hline & \multicolumn{3}{c}{ Forward-Conditioned Group } & & \multicolumn{3}{c}{ Backward-Conditioned Group } \\
\cline { 2 - 5 } & $\mathrm{n}$ & Mean & SE & & $\mathrm{n}$ & Mean \\
\hline Light Flash & 16 & 351.19 & 45.58 & 16 & 78.00 & SE \\
No Light Flash & 16 & 190.81 & 20.79 & 15 & 56.40 & 15.26 \\
\hline
\end{tabular}




\section{EXPERIMENT 2}

Demonstration of a retrograde gradient of effect with a posttraining treatment is generally regarded as evidence that the treatment is modifying memory processes in a retroactive fashion (McGaugh, 1966; Spear, 1978). The demonstration of such a gradient also eliminates proactive effects on performance as an explanation for differences in retention between animals receiving or not receiving the treatment (McGaugh, 1966), since, with a retrograde gradient, the sooner the treatment follows training, the greater the effect on retention performance. The sooner testing follows treatment, the greater should be the proactive consequences of the treatment that influence retention performance during testing.

Experiment 2 was designed to test for timedependent effects of the flashing-light stimulus. The training-treatment intervals used in this study were derived through pilot studies. Based on the results, the intervals of 6 and $12 \mathrm{~h}$ after training were chosen to demonstrate a retrograde gradient of enhancement, with an additional group of rats given the flashing light at $10 \mathrm{sec}$, rather than immediately following training, in order to extend the results reported in Experiment 1 .

\section{Method}

Subjects. The subjects were 115 male Long-Evans rats from the Central Washington University Psychology Department animal colonies, and were 90-120 days of age at the beginning of the experiment.

Apparatus. The training-testing chambers were the same as those used in Experiment 1. In addition, a Plexiglas cylinder $33 \mathrm{~cm}$ high and $30.5 \mathrm{~cm}$ in diameter was used for treatments noncontingent with fear conditioning. Rectangles of white butcher paper $(35 \times 40 \mathrm{~cm})$ placed on a table top served as the floor of the chamber. The paper was changed between animals. The top of the chamber was open and was illuminated by a $25-\mathrm{W}$ bulb hung from the ceiling in a position near the edge of the cylinder and closely approximating the position of the light source in the training and testing chambers. This light was programmed to flash in the same pattern as described for light flash in Experiment 1, with the initiation of the flash condition controlled from a room adjacent to the one in which the noncontingent chamber was housed.

Procedure. Animals were individually housed and maintained on food and water ad lib throughout the experiment, except that water was withheld $24 \mathrm{~h}$ prior to drink training and testing, as in Experiment 1.

During the first 5 days, the experimental procedure was the same as that described for Experiment 1, with the addition of a second session on Days 2 through 5 in which a different experimenter handled the animals. This second session was added to familiarize the animals with the Plexiglas cylinder. Six to $12 \mathrm{~h}$ after the regular daily session, the second experimenter placed each rat in the cylinder, with the light on. The animal remained there for $5 \mathrm{~min}$ and was then returned to the home cage. On Day 6, the animals were randomly assigned to one of eight groups. Forwardconditioned and backward-conditioned animals were conditioned as described in Experiment 1. Some animals in both conditions were given the 60-sec pattern of light-flash stimulation in the training-testing chambers $10 \mathrm{sec}$ after the tone and were removed to the home cage $10 \mathrm{sec}$ after the stimulation offset. All other animals remained in the training-testing chambers an equivalent amount of time. Animals receiving light-flash treatment 6 or $12 \mathrm{~h}$ after training were removed from the home cage at the appropriate interval by the second experimenter and placed in the noncontingent chamber for $5 \mathrm{~min}$. When presented, the 60 -sec pattern of light-flash stimulation was given such that the animals were removed to the home cage $10 \mathrm{sec}$ after the offset of the stimulation. In addition, the rats that were assigned to the 10-sec and nolight-flash conditions were also placed in the noncontingent chamber for 5 min either 6 or $12 \mathrm{~h}$ after the initial training session. In short, all animals were placed in the training-testing chambers and the noncontingent chamber on the training day for equal periods of time.

The use of the Plexiglas cylinder for delivery of the light flash at the longer training-treatment intervals served to eliminate cues of the training situation that may have resulted in memory reactivation (DeVietti et al., 1977). This procedure insured that a temporal gradient of effect on retention performance would more clearly reflect the effect of the treatment on the training trial rather than on a reactivated memory.

\section{Results}

The data from seven animals were eliminated due to procedural errors.

The amount of time to complete 100 licks from the drinking tube on the test day was analyzed with a $2 \times 4$ unweighted means analysis of variance. The analysis revealed no effect of the training conditions, the light flash condition, or their interaction $[F(1,100)$ $>1 ; \mathrm{F}(3,100)=1.36, \mathrm{p}>.05 ; \mathrm{F}(3,100)>1$, respectively].

Data on the latency of the additional 10 licks in the presence of the test tone are summarized in Figure 1. A $2 \times 4$ unweighted means analysis of variance revealed significant effects of training conditions $[F(1,100)=172.92, p<.001]$, of the light-flash conditions $[F(3,100)=5.20, p<.01]$, and of the interaction of these two variables $[F(3,100)=3.19, p<.03]$. Analysis of the simple main effects of this interaction revealed that light flash did not differentiate retention performance in the backward-conditioned groups

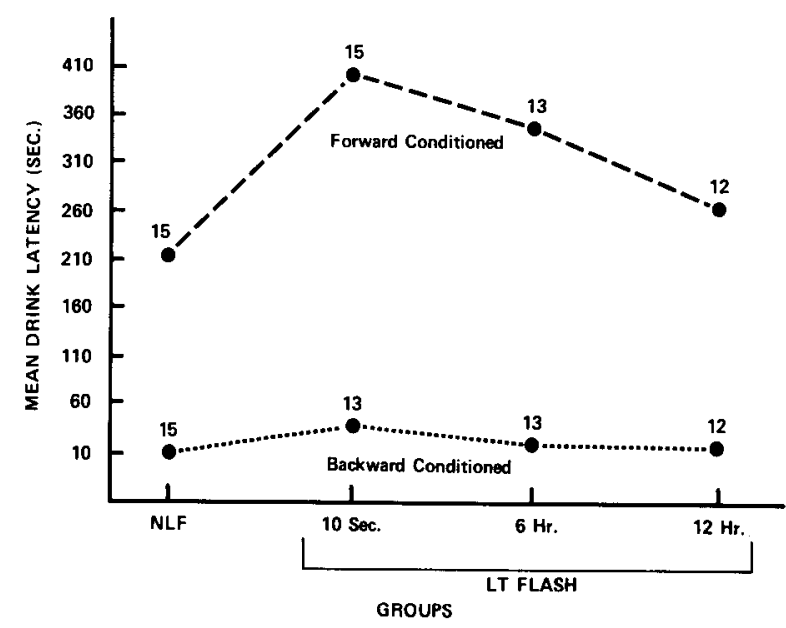

Figure 1. Drink latencies in the presence of the test tone. The number of animals in each group is shown above each data point. 
$[F(3,100)>1]$. However, in the forward-conditioned groups, the light flash did modify retention $[F(3,100)$ $=12.93, \mathrm{p}<.001]$. Pairwise comparisons using the Newman-Keuls procedure with alpha set at .05 revealed longer drink latencies in the presence of the test tone for animals receiving light flash $10 \mathrm{sec}$ or $6 \mathrm{~h}$ after training than for animals experiencing no light flash. Animals receiving light flash $10 \mathrm{sec}$ or $6 \mathrm{~h}$ after training had longer drink latencies than did animals receiving light flash $12 \mathrm{~h}$ after training. Also, as part of the breakdown of the interaction of groups and light flash, forward conditioning resulted in longer drink latencies than did backward conditioning, under all light flash conditions (all ps $<.001)$.

\section{Discussion}

The results of this experiment demonstrate a timedependent effect of the flashing light following fear conditioning. As in Experiment 1, the effects were specific to conditioning, since no effects were obtained in the 100 lick measure prior to the presentation of the tone. For the intervals tested, the maximum retention performance was obtained when the light flash was presented $10 \mathrm{sec}$ after training. The enhancement effect had decreased, but was still evident, at $6 \mathrm{~h}$, and there was a return to baseline at $12 \mathrm{~h}$.

It is important to note that all the animals received a second daily session, in which they were individually carried to the noncontingent chamber and allowed to remain there for $5 \mathrm{~min}$. On the training day, then, the only difference was whether or not the animal received $60 \mathrm{sec}$ of light flash during the training period or during the 5 -min session 6 or $12 \mathrm{~h}$ after training. The treatment on the training day was otherwise the same for all animals within the forwardconditioned group and within the backwardconditioned group. Therefore, it is reasonable to conclude that the differences in retention performance were due to differential experience with the flashing light rather than to the experimenter or apparatus.

As was found in Experiment 1, the light flash had no measurable effect on retention in the backwardconditioned animals even though these animals had experienced both footshock and tone. Also, in the forward-conditioned groups, as the training-treatment interval increased, the influence of the flashing light on retention decreased.

These findings suggest that the results of this experiment are not due to any spurious effects of the footshock, tone, and light flash presentations or to any proactive effects of the light flash on test performance. Rather, these data extend the finding that the flashing light increases retention performance and demonstrates a time-dependent effect of this treatment.

\section{GENERAL DISCUSSION}

Experiment 1 demonstrated that the presentation of a flashing light immediately following fear conditioning enhanced retention performance in testing given after $24 \mathrm{~h}$. Experiment 2 extended this result by demonstrating a temporal gradient of enhancement: presentation of the flashing light $10 \mathrm{sec}$ or $6 \mathrm{~h}$, but not $12 \mathrm{~h}$, after fear conditioning increased retention performance.

One possible explanation of these results involves a contextual change which differed between training and testing. The flashing light was absent in both the training and testing condition in some groups, whereas in other groups, this treatment was present during training but absent in the test. It might be argued that this contextual change influenced the drink latencies in the retention test. However, if this contextual change were operating to alter performance, it is not clear why such an effect would be restricted to the forward-conditioned groups. Also, in Experiment 2 , the similarity of performance in the forwardconditioned group given light flash at $10 \mathrm{sec}$ in the training chamber and the group given light flash at $6 \mathrm{~h}$ in a different chamber seems to argue against a contextual change interpretation.

Another explanation for the present findings might be that the flashing light, either alone or in combination with footshock, was aversive and therefore served as a more effective noxious stimulus than footshock alone. This view, while possibly explaining the performance of groups given the flashing light immediately or $10 \mathrm{sec}$ after the tone and footshock pairing, appears to fall short of explaining the enhanced retention performance in animals given the light flash $6 \mathrm{~h}$ after the tone and footshock in Experiment 2. In addition, there are data indicating that a flashing light is not aversive to the rat. For example, D'Amato (1961) used a flashing light $(1 \mathrm{~Hz})$ similar to the one used in our experiments and found that rats failed to show a preference between the stimulus and a constant light in a Y-maze when the animals were food reinforced for either choice over 20 days, with 20 trials administered each day. Other rats did acquire a discrimination when either stimulus was differentially reinforced. Moreover, we recently reported (DeVietti et al., 1981) that presentation of a flashing light after each preexposure trial to a tone in a latent inhibition paradigm resulted in increased latent inhibition (decreased drink latencies) in the presence of the tone following fear conditioning in which the tone was paired with footshock. If the flashing light had been aversive, decreased latent inhibition (increased drink latencies) would have been expected.

In another attempt to detect aversive qualities of the flashing light (unpublished), we allowed rats to modulate this stimulus in a tilt-box similar to that 
described by Valenstein and Meyers (1964). In accordance with the basic procedure used previously to test for aversive properties of MRF stimulation (DeVietti \& Kirkpatrick, 1977), rats were handled for several days and allowed to explore the tilt box, which was illuminated with a $25-\mathrm{W}$ bulb mounted above its center. On test days, the animals were given a 20-min test session in which the light was randomly programmed to flash for 1-min intervals in series with microswitches located at either end of the apparatus. Thus, rats could initiate or terminate the flashing light by moving from one side of the apparatus to the other. In one experiment, 14 rats were tested in this manner for 2 consecutive days. That these animals failed to modulate the flashing light on either test day was demonstrated by the fact that the mean number of seconds of flashing light received on each day (603 and $606 \mathrm{sec}$, respectively) failed to differ from either the expected mean of $600 \mathrm{sec}$ in the presence of the light flash or from the means for a group of 13 rats that did not receive the flashing light but whose positions in the apparatus were recorded during intervals when light flash would have occurred (means $=598$ and $597 \mathrm{sec}$, respectively).

Although rats in our laboratory modulate even weak footshock $(.5 \mathrm{~mA})$ in their initial test session, we tested the possibility that animals may not be able to learn to modulate the flashing light as rapidly. Six rats were allowed to modulate a .7-mA footshock for 2 successive test days and then were tested with the light flash the following day. Again, no evidence that the flashing light was aversive was obtained: these animals spent an average of $589 \mathrm{sec}$ in the presence of the stimulus, although they clearly had modulated the footshock on the previous 2 days (means = 134 and $111 \mathrm{sec}$, respectively). Finally, we tested the possibility that the presentation of the flashing light may become aversive following footshock. Another 6 rats were given a single footshock, of the same duration and intensity as in Experiments 1 and 2, in the tilt box and then given a test session $10 \mathrm{sec}$ later. These animals spent an average of $576 \mathrm{sec}$ in the presence of the flashing light. In short, we have been unable to demonstrate that the flashing light, either alone or following footshock, is aversive, and we conclude that aversiveness of the light flash is not an acceptible explanation of our results.

Thus, we conclude that neither a contextual change nor aversiveness of the flashing light appears adequate to explain the results of Experiments 1 and 2. Based on the fact that the time-dependent modification of retention performance shown in Experiment 2 clearly satisfies the criterion generally accepted as evidence for such an interpretation, we suggest that the flashing light enhances memory processes under these conditions.

The present results may have important implica- tions for current speculation regarding the mechanism by which experimental treatments modify memory processing. We find it interesting, as well as somewhat disconcerting when one considers cost, time, and talent, that we can obtain very similar effects on retention performance by stimulating the MRF and by simply flashing the houselight (cf. DeVietti et al., 1977; DeVietti \& Kirkpatrick, 1977; DeVietti et al., 1981; the present experiments). To date, the only discrepancy in the effects of these two treatments appears to be in the length of the enhancement gradient, a fact which may simply reflect a parametric problem. It will be of interest to determine if the enhanced retention effected by these two treatments results from the same mechanism. In this regard, it is worth noting that, in one of the first papers reporting enhancement of retention with stimulation of the MRF, Bloch (1970) suggested that the effect on memory was indirectly the result of increased arousal induced by the stimulation.

\section{REFERENCES}

BLoch, V. Facts and hypotheses concerning memory consolidation processes. Brain Research, 1970, 24, 561-575.

D’Aмато, M. R. Flash rate as a discriminandum in discrimination learning in rats. Journal of Comparative and Physiological Psychology, 1961, 54, 445-448.

DeVietTi, T. L., Conger, G. L., \& Kirkpatrick, B. R. Comparison of the enhancement gradients of retention obtained with stimulation of the mesencephalic reticular formation after training or memory reactivation. Physiology \& Behavior, 1977, 19, 549-554.

DeVietTi, T. L., \& KinkPatRick, B. R. Stimulation of specific regions of brain in rats modifies retention for newly acquired and old habits. Journal of Comparative and Physiological Psychology, 1977, 91, 662-673.

DeVietti, T. L., Wittman, T. K., Emmenson, R., \& Thatcher, D. O. Either stimulation of the mesencephalic reticular formation or a flashing light increases latent inhibition to a toneconditioned stimulus. Behavioral and Neural Biology, 1981, 32, 308-318.

Lubow, R. E., Schnur, P., \& Rifkin, B. Latent inhibition and conditioned attention theory. Journal of Experimental Psychology: Animal Behavior Processes, 1976, 2, 163-174.

Mackintosh, N. J. A theory of attention: Variations in the associability of stimuli with reinforcement. Psychological Review, 1975, 82, 276-298.

McGaugh, J. L. Time-dependent processes in memory storage. Science, 1966, 153, 1351-1358.

Solomon, P. R., \& Moore, J. W. Latent inhibition and stimulus generalization of a classically conditioned nictitating membrane response in rabbits (Oryctolagus cuniculus) following dorsal hippocampal ablation. Journal of Comparative and Physiological Psychology, 1975, 89, 1192-1203.

SPEAR, N. E. The processing of memories: Forgetting and retention. Hillsdale, N.J: Erlbaum, 1978.

Valenstein, E. S., \& MEYERS, W. J. Rate-independent test of reinforcing consequences of brain stimulation. Journal of Comparative and Physiological Psychology, 1964, 57, 52-60.

(Manuscript received October 28, 1981; revision accepted for publication March 23, 1982.) 